\title{
Formulation and Evaluation of Fast Dissolving Tablet Containing Vilazodone Nanocrystals for Solubility and Dissolution Enhancement Using Soluplus: In vitro-In vivo Study
}

\author{
S. G. Gattani, R. S. Moon* \\ School of Pharmacy, Swami Ramanand Teerth Marathwada University, Nanded, Maharashtra, 431606, India.
}

\begin{tabular}{l}
\hline ARTICLE INFO \\
\hline Article history: \\
Received on: $15 / 01 / 2018$ \\
Accepted on: $24 / 03 / 2018$ \\
Available online: $30 / 05 / 2018$
\end{tabular}

Key words:

Vilazodone nanocrystals,

Soluplus, solubility.
Fast dissolving tablet,

\begin{tabular}{l} 
ABSTRACT \\
\hline A major problem in the development of an efficacious formulation of the drug is its pitiable aqueous solubility which \\
affects stability and bioavailability of drug formulation. There is a need for systematic formulation approaches to make \\
poorly soluble drugs bioavailable. The present investigation aims to increase solubility and dissolution of Vilazodone \\
(VLZ) an antidepressant drug by preparing its nanoparticles using graft copolymer Soluplus and polyvinylpyrrolidone \\
K-30 (PVP K 30) by evaporative precipitation into aqueous solution method. The prepared nanoparticles were \\
characterized by FTIR, DSC, XRD, SEM, Particle size by DLS and saturation solubility. The nanoparticles showed \\
a remarkable increase in the aqueous saturation solubility i.e., NP1, NP2, NP3 and NP4 shows 4.4, 4.6, 7.7 and 7.8 \\
folds respectively increase in aqueous solubility as compared to VLZ. The nanoparticles NP4 batch with the highest \\
solubility is converted into fast dissolving tablet. The tablets were evaluated for different parameters and found to \\
possess more dissolution ( $89.386 \%$ release) as compared to pure drug (51.652\%). The rise in solubility and dissolution \\
may be due to either reduction in particle size leads to increase surface area or micelles formation due to Soluplus \\
and reduction in crystallinity of drug. In vivo study reveals that optimized Vilazodone nanoparticles (VLZNP) elicited \\
significant antidepressant-like activity.
\end{tabular}

\section{INTRODUCTION}

Therapeutic efficacy depends upon bioavailability, solubility, and release of drug molecules from the formulation. The aqueous solubility of therapeutically active substance governs dissolution, absorption and has an essential role in bioavailability of oral drug formulations (Patel et al., 2011). About more than $40 \%$ of drug molecules recognized during combinatorial selection programs are poorly water soluble. Low aqueous solubility is main trouble in formulation development, clinical testing and during screening new compounds for therapeutic activity (Lipinski, 2002). The low water solubility of many active pharmaceutical ingredients (APIs) excludes their use in certain clinical applications in spite of their efficacy. However, small particle formation technologies for these APIs may increase

${ }^{*}$ Corresponding Author

R. S. Moon, School of Pharmacy, Swami Ramanand Teerth Marathwada

University, Vishnupuri, Nanded, Maharashtra, 431606, India.

E-mail: rajmun@rediffmail.com their effectiveness for oral, injectable and inhalation delivery by increasing surface area, dissolution rates and overall bioavailability (Vaughn et al., 2004). Systematic formulation approaches may make poorly soluble drugs bioavailable. Nanoparticle engineering technologies in formulation development of low water-soluble drugs is a promising strategy to enhance dissolution rates and thus bioavailability (Patel et al., 2011). Vilazodone is an antidepressant agent with poor aqueous solubility use as an alternative for patients who cannot tolerate treatment with other antidepressants.

\section{MATERIALS AND METHODS}

\section{Materials}

Vilazodone was gifted by Clearsynth labs Pvt Ltd Mumbai, Soluplus a graft copolymer was a gift sample from BASF chemicals, Mumbai, PVP K-30, and microcrystalline cellulose was from Himedia Lab. Pvt. Ltd., Mumbai, all other materials and chemicals were procure from S D Fine chemicals Mumbai. 


\section{Methods}

\section{Preparation of nanoparticles}

Nanoparticles were prepared by evaporative precipitation into aqueous solution method. Vilazodone was dissolved in dimethyl sulfoxide with warm at $70-80^{\circ} \mathrm{C}$ under constant stirring at $1000 \mathrm{rpm}$. The prepared drug solution was injected dropwise by using syringe into water containing soluplus with stirring on a magnetic stirrer at $1000 \mathrm{rpm}$, particles precipitated and milk like suspension formed in which added solution of PVP K-30. Resultant was then filtered and dried. Nanoparticles were ground in mortar and pestle and pass through sieve no 170 to obtain desired uniform size. The Nanoparticles of the drug with polymer was denoted with symbol VLZNP.

\section{Ratio optimization (drug: polymer) by solubility study}

The solubility of VLZNP determined in distilled water. The solubility of NPs was determined by taking an excess amount of NPs and adding them to $10 \mathrm{ml}$ of Millipore water and kept at equilibrium on a magnetic stirrer for a period of 48 hours (REMI Instruments, Mumbai) at room temperature. The resultant was filtered through $0.45 \mu \mathrm{m}$ nylon syringe filter and analyzed by UV-Visible spectrophotometer (Shimadzu Corporation, Japan) at $224 \mathrm{~nm}$ wavelength. Ratio (drug: carrier) with higher solubility was said to be optimized and processed further.

\section{Drug entrapment efficiency of NPS}

The Vilazodone percentage entrapped within nanoparticles determined by measuring the concentration of free Vilazodone in the dispersion medium.

$$
\% \mathrm{EE}=\left(\left[\mathrm{M}_{\text {initial drug }}-\mathrm{M}_{\text {free drug }}\right] \times 100\right) /\left(\left[\mathrm{M}_{\text {initial drug }}\right]\right),
$$

where $M_{\text {initial drug }}$ is the mass of initial drug used for the assay, $\mathrm{M}_{\text {free drug }}$ is the mass of free drug detected in the supernatant after centrifugation of the aqueous dispersion.

\section{In-vitro dissolution test for VLZ nanoparticles}

Dissolution of optimized ratio performed using USP type II dissolution apparatus (Electrolab) in $900 \mathrm{ml}$ of $0.1 \mathrm{~N} \mathrm{HCl}$. Powder containing $40 \mathrm{mg}$ (or equivalent) of Vilazodone added in medium maintaining temperature $37 \pm 0.5^{\circ} \mathrm{C}$ and $50 \mathrm{rpm}$ paddle speed. About $5 \mathrm{ml}$ of aliquot were withdrawn at 2.5, 5, 10, 15, 20,25 and 30 minute and replaced with the same quantity of prewarmed fresh dissolution medium. Aliquots filtered through $0.45 \mu \mathrm{m}$ nylon syringe filter and analyzed spectrophotometrically at a wavelength of $224 \mathrm{~nm}$ (Medina et al., 2013; Javadzadeh et al., 2007).

\section{Characterization of nanoparticles}

Nanoparticles which show better results in solubility and in vitro dissolution were further characterized to access interaction if any between drug and polymer during a month.

\section{Fourier-transform infrared spectroscopy}

Spectra of drug Vilazodone alone and its Nanoparticles carried out to check compatibility of the drug with polymers. The nanoparticle of the drug with the polymer (VLZNPs) triturated with potassium bromide IR grade. The dispersion was scanned using FT-IR Spectrophotometer (Shimadzu, Japan). The spectra of nanoparticles compared with the Spectra of vilazodone.

\section{Differential scanning calorimeters (DSC)}

DSC thermograms of drug Vilazodone and its nanoparticles obtained (Diamond DSC, Perkin Elmer) by heating at a rate of $10^{\circ} \mathrm{C} / \mathrm{min}$ from temperature $0-300^{\circ} \mathrm{C}$.

\section{$X$-ray diffraction studies $(X R D)$}

XRD study of drug Vilazodone and Nanoparticles access the changes in crystallinity of drug alone and when combined with the polymer. XRD patterns recorded using (Bruker, D8) with $\mathrm{Cu}-\mathrm{k} \alpha$ radiation. The scanning angle ranged from $20^{\circ}$ to $80^{\circ}$ of $2 \theta$.

\section{Scanning electron microscopy (SEM)}

The surface morphology of nanoparticle formulation was examined by Scanning Electron Microscopy with Gold ion coating for 5-6 $\mathrm{min}$.

\section{Particle size}

Particle size was studied by Dynamic Light Scattering method (Hackley and Clogston, 2007).

\section{Preparation of fast dissolving tablet}

The ratio of NPs which shows best results in solubility and powder dissolution was selected for preparation of fast dissolving tablet, table 2 . The tablets were compressed by direct compression method using $10 \mathrm{~mm}$ punch on rotary tablet Minipress (Karnavati Pvt. Ltd, Gujarat).

Table 1: Formulation design of nanoparticles.

\begin{tabular}{cccccccc}
\hline Ingredients & NP1 & NP2 & NP3 & NP4 & NP5 & NP6 & NP7 \\
\hline Vilazodone & 200 & 200 & 200 & 200 & 200 & 200 & 200 \\
Soluplus & 200 & 300 & 400 & 500 & 600 & 700 & 800 \\
PVP K-30 & 100 & 100 & 100 & 100 & 100 & 100 & 100 \\
\hline
\end{tabular}

Table 2: Composition of VLZNP Fast dissolving tablet.

\begin{tabular}{cccc}
\hline \multirow{2}{*}{ Ingredients } & \multicolumn{3}{c}{ Batches (All ingredients were in $\mathbf{~ m g})$} \\
\cline { 2 - 4 } & $\mathbf{F}_{\mathbf{1}}$ & $\mathbf{F}_{\mathbf{2}}$ & $\mathbf{F}_{3}$ \\
\hline VLZNP (equivalent to 40 mg Vilazodone) & 160 & 160 & 160 \\
Microcrystalline cellulose & 80 & 80 & 80 \\
Sodium starch glycolate & 40 & 35 & 30 \\
Magnesium stearate & 6 & 6 & 6 \\
Talc & 4 & 4 & 4 \\
Starch & 10 & 15 & 20 \\
Total final weight & 300 & 300 & 300
\end{tabular}

Pre and post compression evaluation of tablet

Precompression and Post compression evaluation fast dissolving tablet were performed according to USP 30 NF 25 (Rockvillle, 2007). 


\section{In vitro dissolution test for fast dissolving tablet}

In vitro dissolution test was performed according to USP apparatus Type II (Electrolab). Tablet containing $40 \mathrm{mg}$ (or equivalent) of Vilazodone was added in dissolution media 900 $\mathrm{ml}$ gastric fluid maintaining the temperature at $37 \pm 0.5^{\circ} \mathrm{C}$ and rotation speed of paddle at $50 \mathrm{rpm}$. About $5 \mathrm{ml}$ of the aliquot were withdrawn at 2.5, 5, 10, 15, 20, 25, 30 and 35 minute and replaced with $5 \mathrm{ml}$ of fresh prewarmed gastric fluid, filtered through 0.45 $\mu \mathrm{m}$ nylon syringe filter and analyzed at $224 \mathrm{~nm}$ wavelength.

\section{Stability studies}

Optimized tablet formulation containing nanoparticles subjected to stress conditions of $40^{\circ} \mathrm{C} / 75 \% \mathrm{RH}$ for six months in stability chamber (Photostability chamber S R Lab Instruments Pvt. Ltd. Mumbai).

\section{In vivo antidepressant activity evaluation}

The study was conducted in compliance the protocol approved by the institutional ethical committee. Immobility time in mice evaluated as per the method described by (Porsolt et al., 1977). Mice were forced to swim in an open cylindrical container (diameter $10 \mathrm{~cm}$, height $25 \mathrm{~cm}$ ) containing $19 \mathrm{~cm}$ of water (depth) at $25 \pm 1{ }^{\circ} \mathrm{C}$; and the immobility time recorded for 6 minutes. Individual mouse considered to be immobile when it ceased struggling and remained floating motionless in the water, showing only those movements essential to keep its head above water. An increase in immobility time was considered an indication of depressive behavior.

\section{RESULT AND DISCUSSION}

\section{Drug: polymer ratio optimization}

NPs of the drug with polymer were analyzed for solubility study and results are shown in table 3 . Solubility study shows that soluplus have very good solubility enhancing property may because of its good surfactant property (Pandey et al., 2012; Hardung et al., 2010). From solubility studies, it is found that up to certain ratio i.e. 1:2.5 solubility goes increases constantly and further increase in polymer concentration leads to decrease in solubility. Prepared nanoparticle samples showed increased solubility in water more than seven-fold higher $(9.36$ $\mu \mathrm{g} / \mathrm{ml})$ than pure Vilazodone $(1.48 \mu \mathrm{g} / \mathrm{ml})$. This optimized ratio was then confirmed with powder dissolution and further used for formulation development. The increase solubility of of Vilazodone from prepared nanoparticles may due to the reduction in particle size.

Table 3: Solubility of pure VLZ and VLZ nanoparticles.

\begin{tabular}{ccc}
\hline \multirow{2}{*}{ Batch code } & \multicolumn{2}{c}{ Water Solubility } \\
\cline { 2 - 3 } & In $(\boldsymbol{\mu g} / \mathbf{m l})$ & Increase (in fold) \\
\hline Pure Drug & 1.486 & 1.0 \\
NP1 & 5.813 & 4.4 \\
NP2 & 6.063 & 4.6 \\
NP3 & 9.251 & 7.7 \\
NP4 & 9.36 & 7.8 \\
NP5 & 9.06 & 7.6 \\
NP6 & 4.726 & 3.3 \\
NP7 & 3.126 & 1.7 \\
\hline
\end{tabular}

\section{Drug entrapment efficiency of Nanoparticles}

Percentage entrapment efficiency of NP4 was found to be maximum that is $95.32 \%$.

\section{In vitro dissolution studies of nanoparticles}

VLZNP powder released $82.36 \%$ of the drug in solution compared to a pure drug which released only $53.75 \%$. From the results fig. 1 it can be concluded that \% drug release of VLZNP is faster than pure VLZ and hence nanoparticles used for the preparation of tablet formulation.

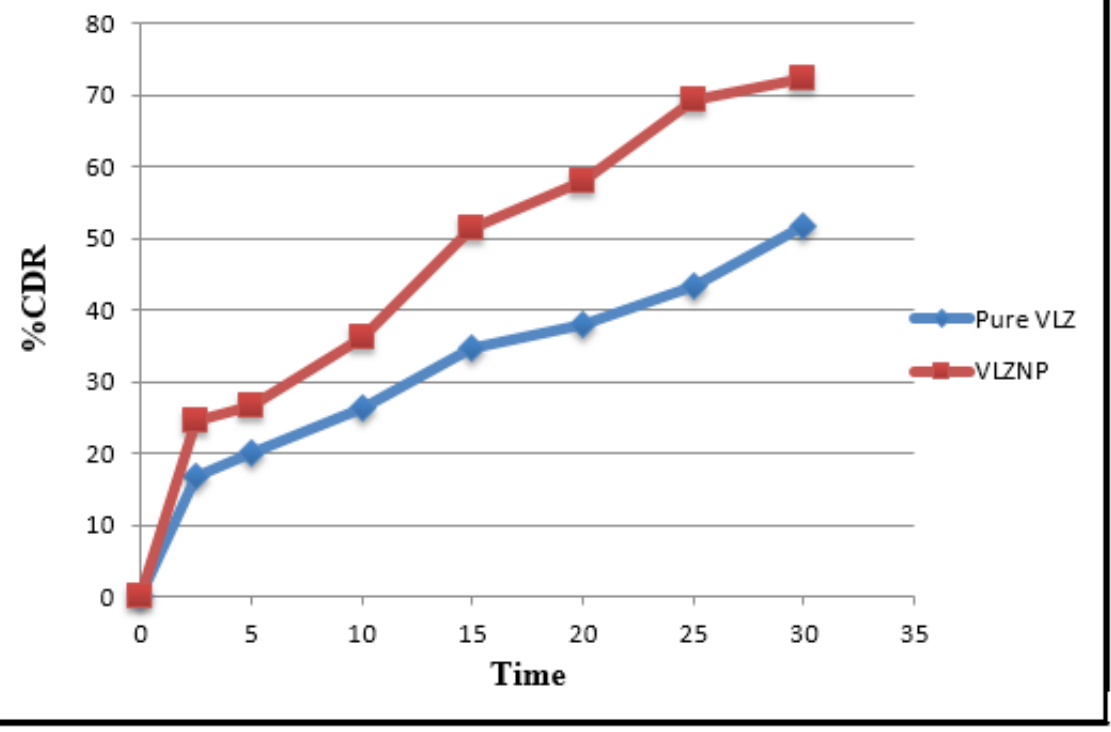

Fig. 1: Comparative Dissolution Profile of pure VLZ and VLZNP. 


\section{Characterization of VLZNPs}

\section{Fourier transformed infrared spectra}

From the spectra of vilazodone and its nanoparticles, it can be concluded that principle peaks of the drug remained unchanged in soluplus treated nanoparticles demonstrating the compatibility between drug and polymer.

\section{Differential scanning calorimetry}

DSC analysis performed to observe the thermal behavior of components used in Nanoparticles formulation. The DSC thermograms of the VLZ and VLZNP fig. 4 and fig. 5 showed a sharp characteristic endothermic peak at $276.62^{\circ} \mathrm{C}$ and $277.31^{\circ} \mathrm{C}$ respectively indicating crystalline nature of materials and there is no appearance or disappearance of one or more peak.

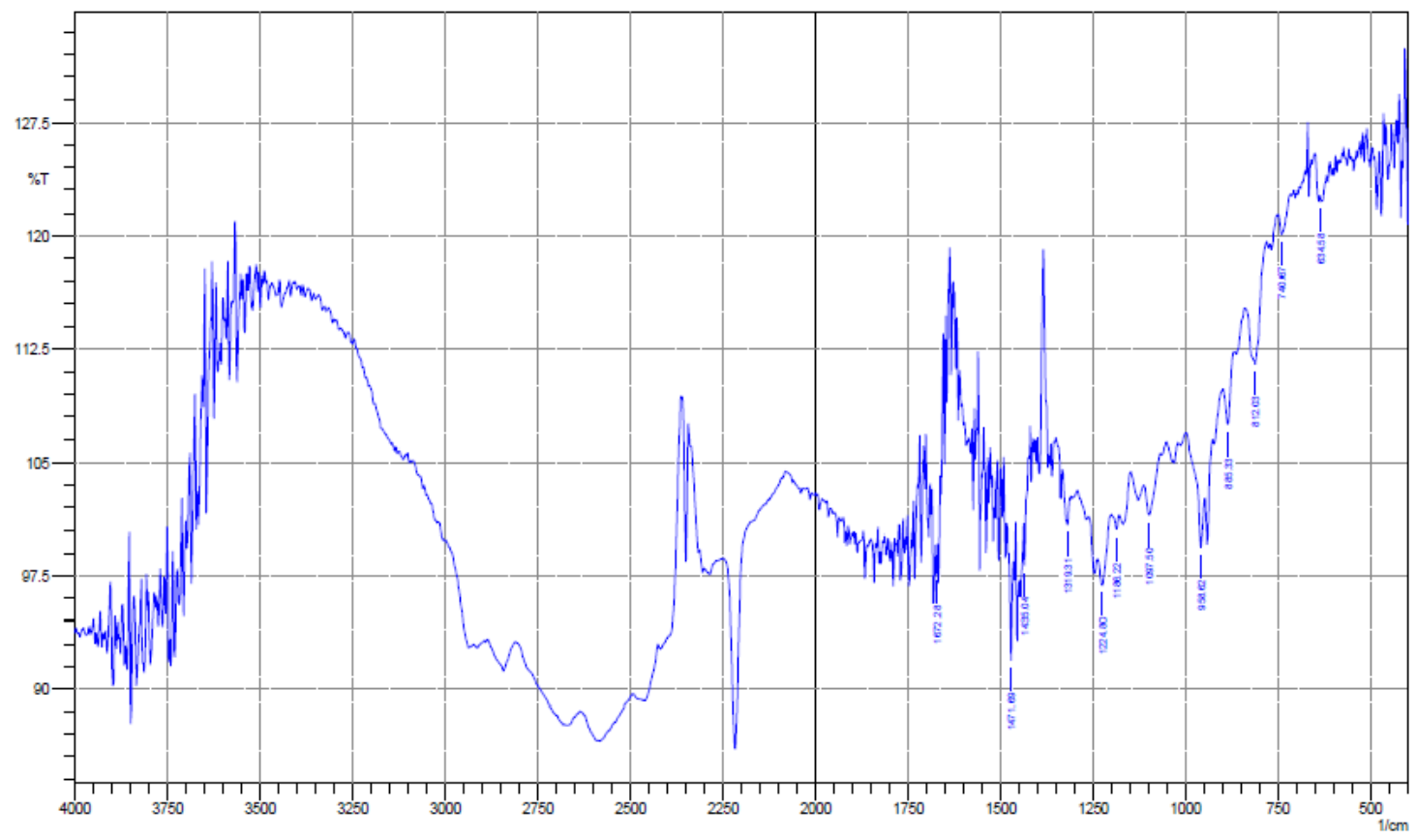

Fig. 2: IR-Spectrum of pure VLZ.

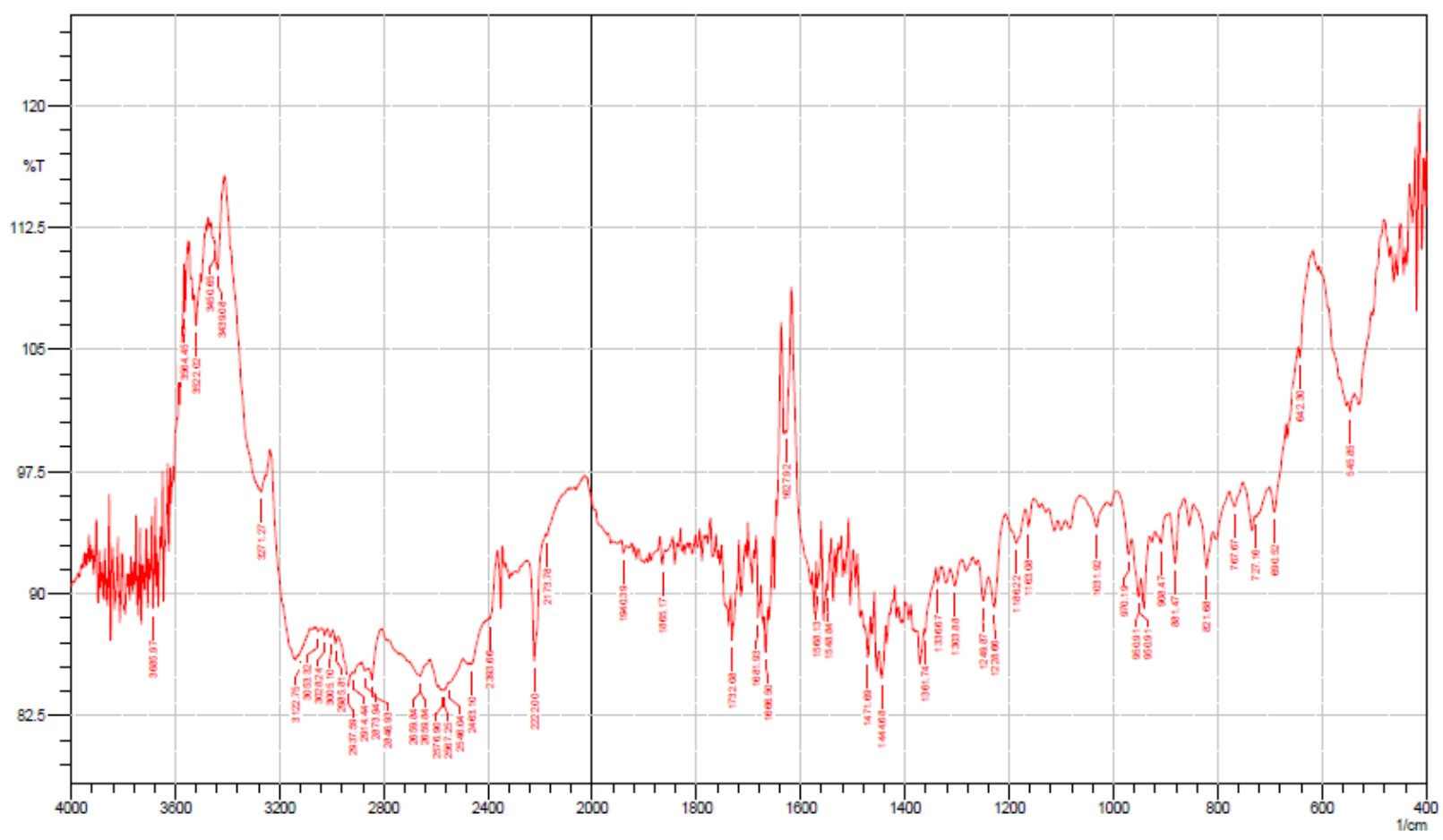

Fig. 3: IR-Spectrum of VLZNPs. 


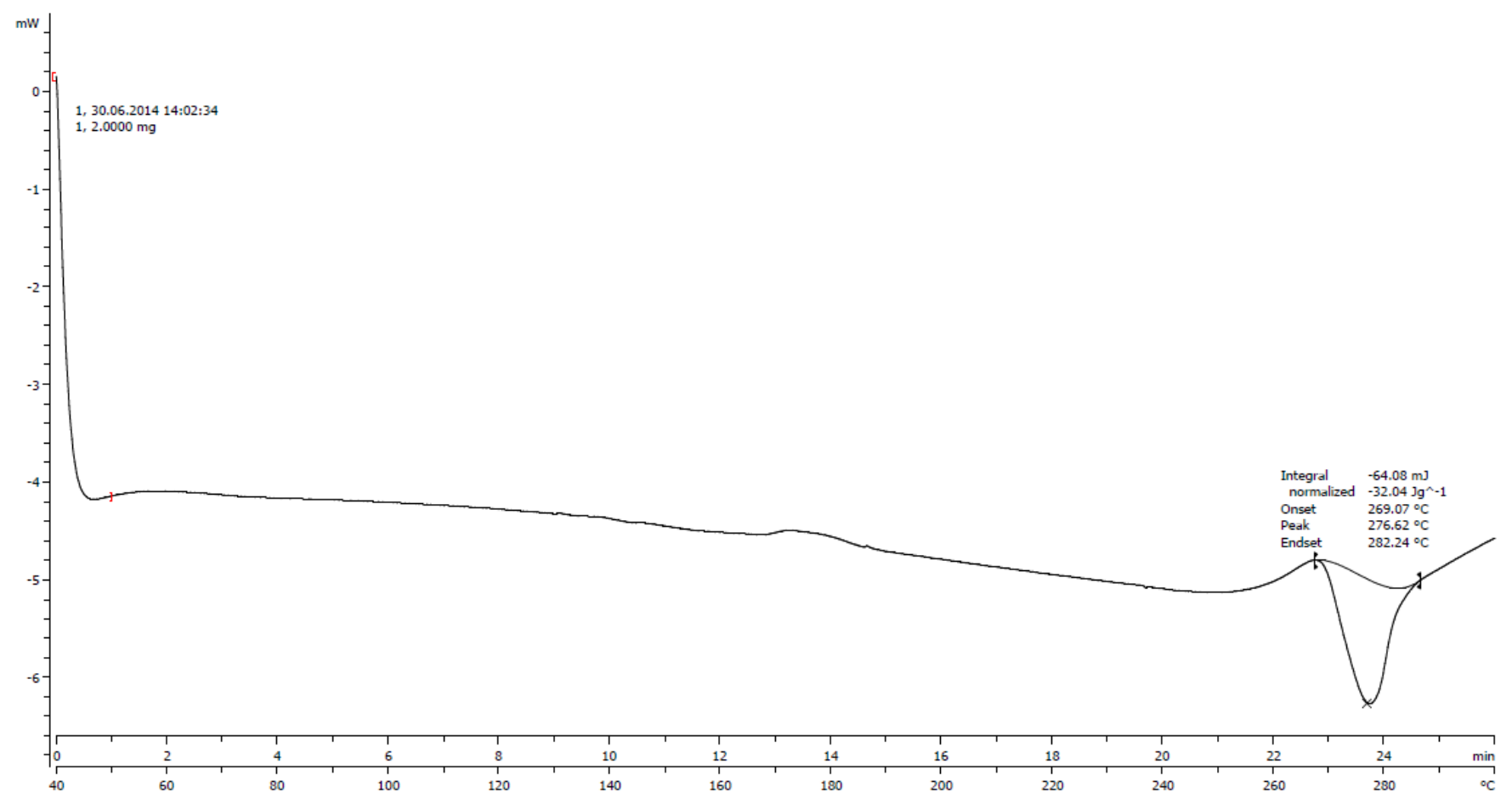

Fig. 4: DSC thermogram of Pure VLZ.

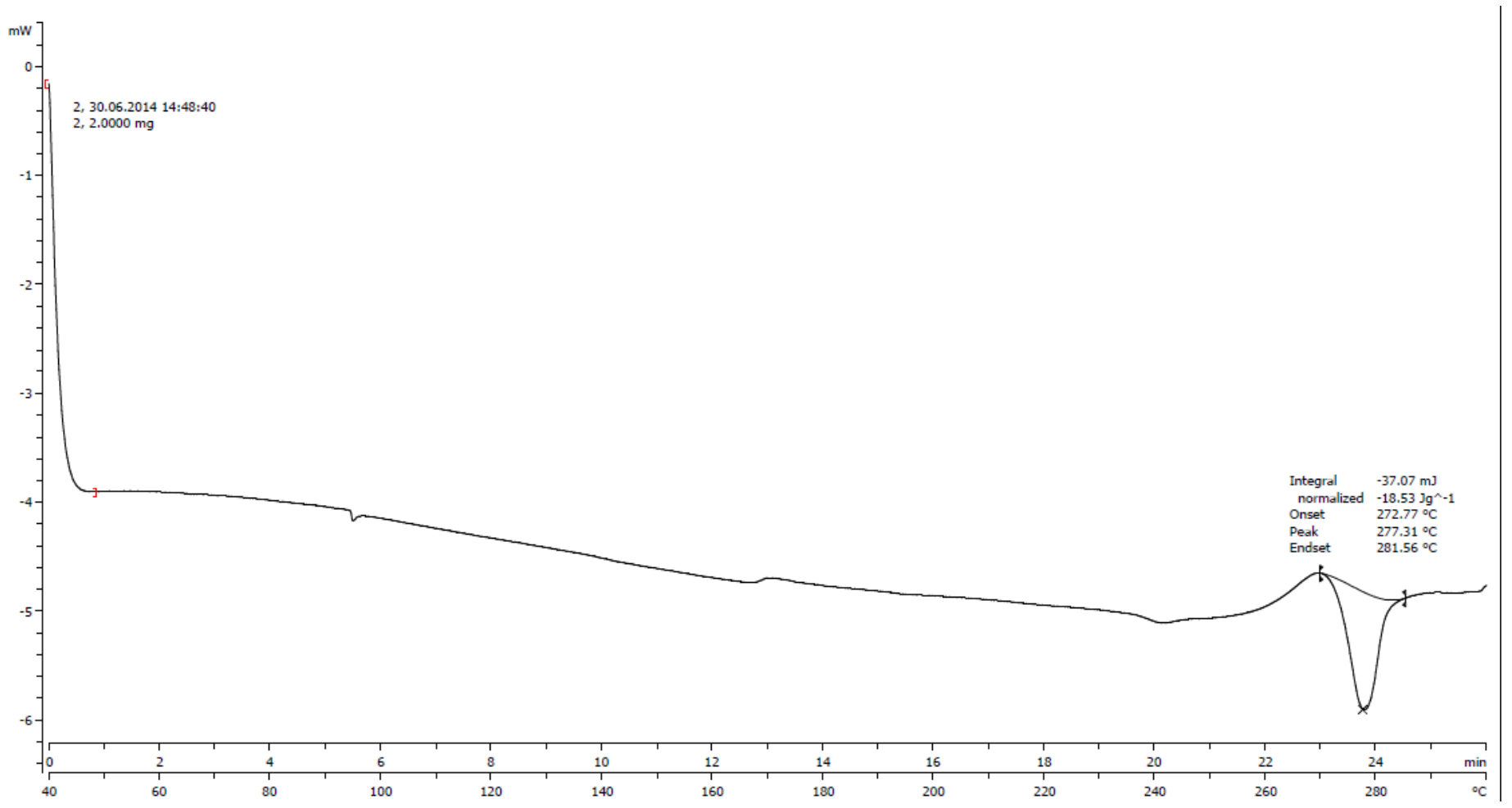

Fig. 5: DSC thermogram of VLZNP. 


\section{$X$-ray powder diffraction $(X R D)$}

Diffractogram of Vilazodone showed numerous sharp peaks between 24.56 to 28.85 at $2 \theta$ and VLZNP showed the presence of less intense peaks between 24.76 to 20.57 at $2 \theta$. The intensity of the peaks reduces indicating that soluplus interferes with the Vilazodone by forming H-bonding and thus reduces the crystallinity of the drug and indicates amorphization of the drug.

Scanning electron microscopy (SEM)

Pure drug particles are tabular while optimized NPs were found to be irregular in shape and size below $1000 \mathrm{~nm}$. The SEM images (fig. 8) clearly indicate a complex form of Vilazodone in Soluplus.

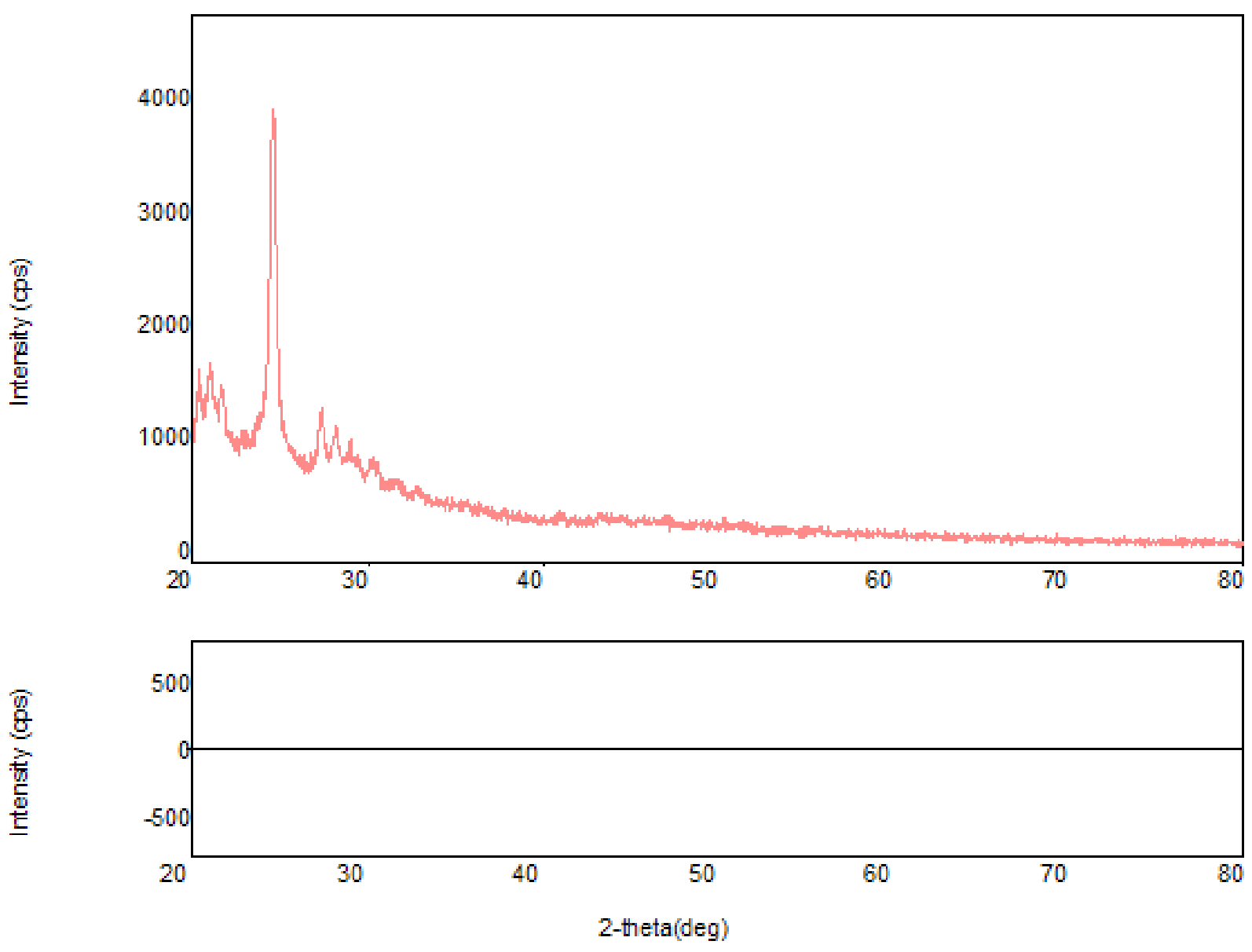

Fig. 6: XRD pattern of Pure VLZ.

Particle size

The Dynamic Light Scattering measurements as depicted in fig. 9 , show $90 \%$ of particles falls below $100 \mathrm{~nm}$ and $10 \%$ of particle found coarser.

Pre and post-compression evaluation of fast dissolving tablet

All the pre and post compression evaluation parameters are found to be within the limit as per USP 30 NF25 results depicted in table 4 and 5 .

\section{In vitro dissolution of VLZNPs fast dissolving tablet}

Release of VLZNPs tablet formulation $\mathrm{F}_{2}(89.386 \%)$ exhibited improved dissolution behavior than formulation $F_{1}$ $(86.74 \%) \mathrm{F}_{3}(84.581)$ and VLZ $(51.65 \%)$ at the end of $30 \mathrm{~min}$, this may due to decreased particle size, increased surface area and micellar effect of soluplus (Gattani et al., 2018). Results of the in-vitro drug release depicted in fig. 10.
Table 4: Pre compression studies.

\begin{tabular}{cccc}
\hline Formulation code & Angle of repose ( $\boldsymbol{\theta})$ & Carr's index (\%) & Hausner's ratio \\
\hline $\mathrm{F}_{1}$ & $21.26 \pm 1.653$ & $10.56 \pm 0.961$ & $1.312 \pm 0.026$ \\
$\mathrm{~F}_{2}$ & $20.56 \pm 1.681$ & $12.64 \pm 0.674$ & $0.989 \pm 0.069$ \\
$\mathrm{~F}_{3}$ & $22.11 \pm 1.388$ & $13.76 \pm 0.766$ & $1.213 \pm 0.156$ \\
\hline
\end{tabular}

Data are means $\pm \mathrm{SD}, n=3$.

Stability study of vilazodone nanoparticles tablet

Optimized formulation $\left(\mathrm{F}_{2}\right)$ subjected to stability conditions $\left(40^{\circ} \mathrm{C} / 75 \% \mathrm{RH}\right)$ and parameters such as color, odor, assay, and release were studied during 180 days of exposure. No significant change was observed in the stability parameters during exposure and formulation said to be stable and not much affected by stress conditions. 
Table 5: Post compression studies.

\begin{tabular}{|c|c|c|c|c|c|}
\hline Batch & Weight variation (mg) & Hardness $\left(\mathrm{kg} / \mathrm{cm}^{2}\right)$ & Friability $(\%)$ & Drug content uniformity (\%) & Disintegration time (Sec) \\
\hline $\mathrm{F}_{1}$ & $297 \pm 4.621$ & $3.8 \pm 0.125$ & $0.39 \pm 0.082$ & 93 & $19 \pm 1.269$ \\
\hline $\mathrm{F}_{2}$ & $301 \pm 3.625$ & $3.6 \pm 0.168$ & $0.43 \pm 0.063$ & 95 & $18 \pm 2.365$ \\
\hline $\mathrm{F}_{3}$ & $293 \pm 3.591$ & $3.7 \pm 0.215$ & $0.38 \pm 0.051$ & 92 & $20 \pm 1.874$ \\
\hline
\end{tabular}

Data are means $\pm \mathrm{SD}, n=3$.
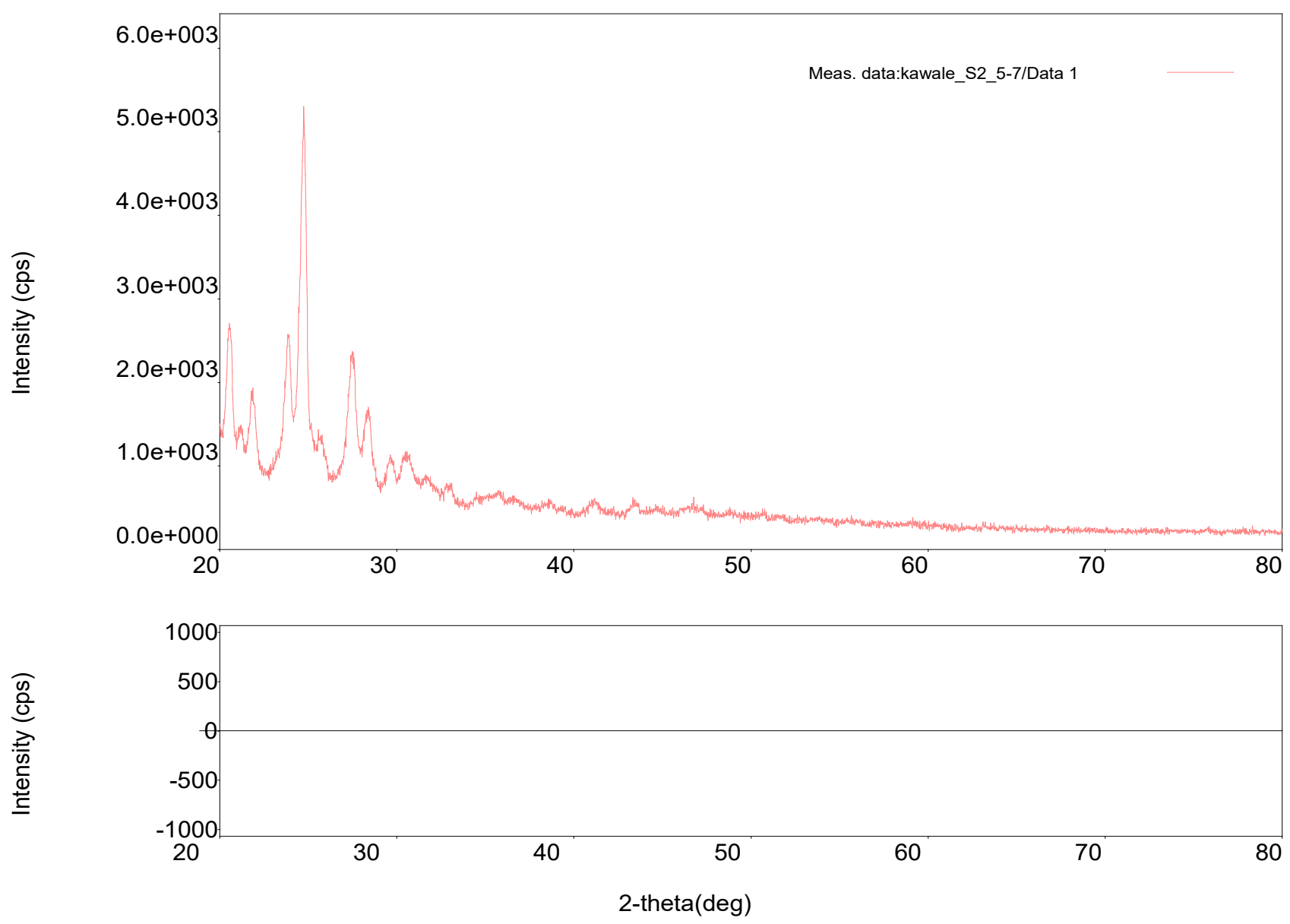

Fig. 7: XRD pattern of VLZNP.

Table 6: Stability data of VLZNPs tablet formulation $\mathrm{F}_{2}$.

\begin{tabular}{ccc}
\hline Time (days) & \% drug content & \% In vitro drug release \\
\hline 0 & 95 & 89.38 \\
30 & 95.30 & 89.43 \\
180 & 95.19 & 89.40 \\
\hline
\end{tabular}

\section{In vivo antidepressant activity evaluation}

Experimental data revealed that mice treated with VLZNP antidepressant agent attenuate significantly $(P<$ 0.001 ) immobility time compared to VLZ and vehicle-treated group (Table $7 \&$ fig 11). From the data, it seems that VLZ and VLZNP elicited significant antidepressant-like activity. This improvement in the effect of VLZNP may govern by the decreased particle size and increased surface area and also may due to the micellar action of Soluplus. Thus raised solubility and the in vitro dissolution are supported by in vivo data and also kinetics.

Table 7: Effects of the vehicle, or VLZ and VLZNP on immobility time in mice.

\begin{tabular}{cc}
\hline Treatment and dose (mg/kg, p.o.) & Immobility time (Sec) \\
\hline Vehicle $(10 \mathrm{ml} / \mathrm{kg})$ & $52.3 \pm 6.9$ \\
VLZ & $46.5 \pm 7.5^{\text {ns }}$ \\
VLZNP & $24.5 \pm 3.2^{* *}$
\end{tabular}

Results are expressed as Mean \pm SEM, $(n=6)$, Data was analyzed by one-way ANOVA followed by Dunnett's test, ${ }^{*} P<0.05,{ }^{*} P<0.001$, NS-Nonsignificant when compared to vehicle-treated group. 


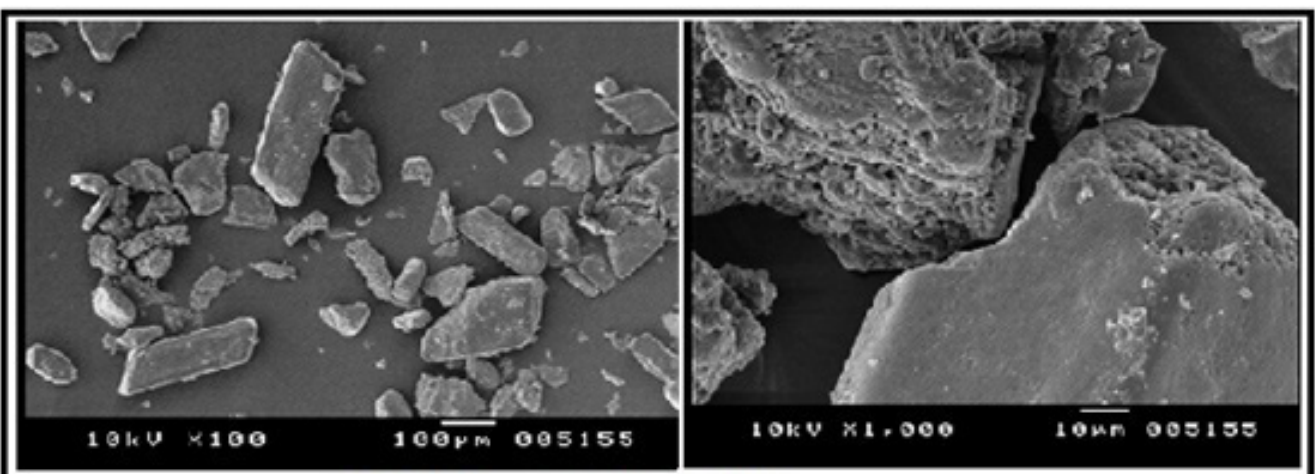

A) SEM images of pure VLZ

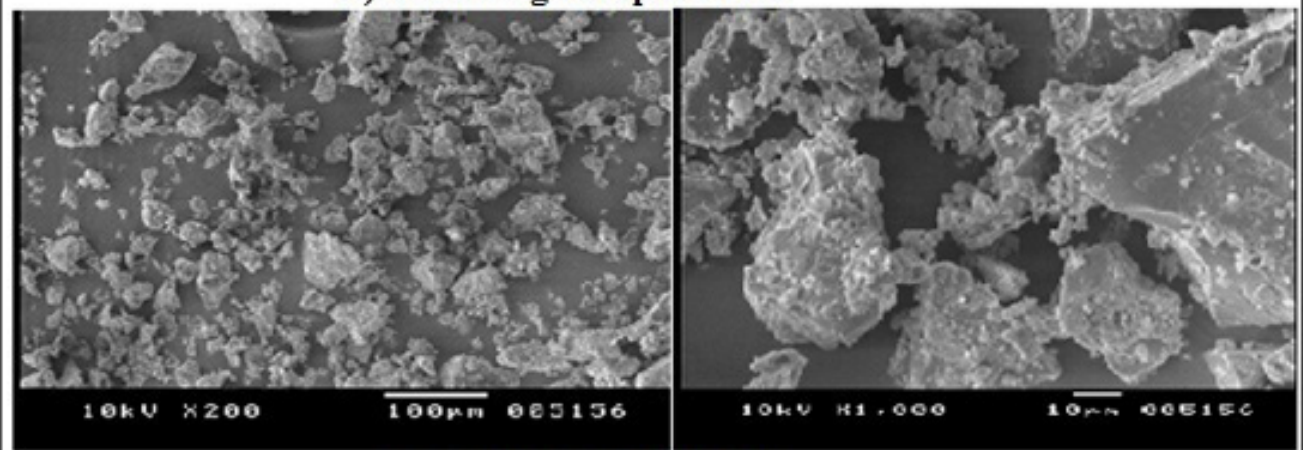

B) SEM images of VLZNP

Fig. 8: SEM images of pure VLZ and VLZNP.

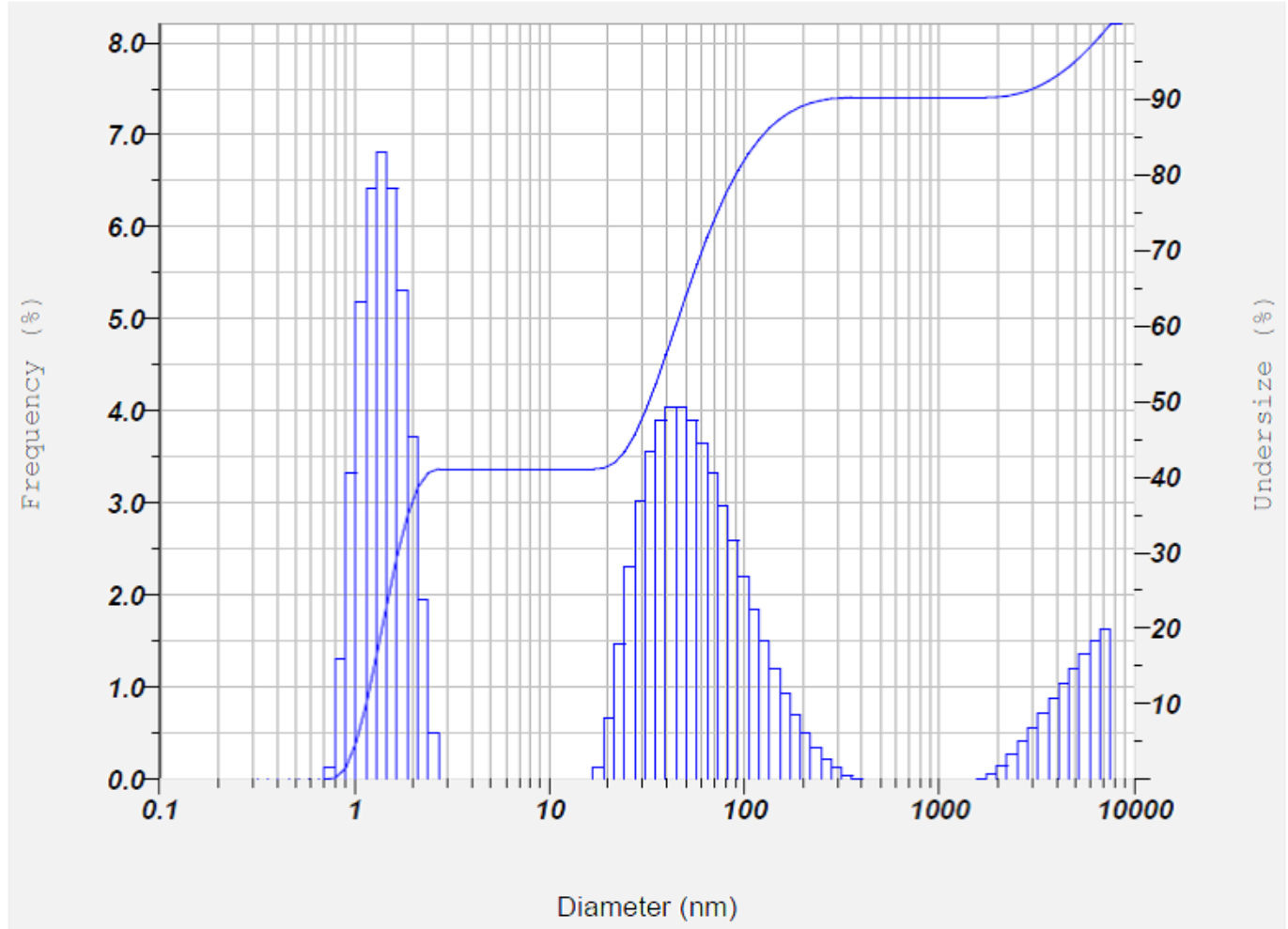

Fig. 9: Particle size of VLZNP. 


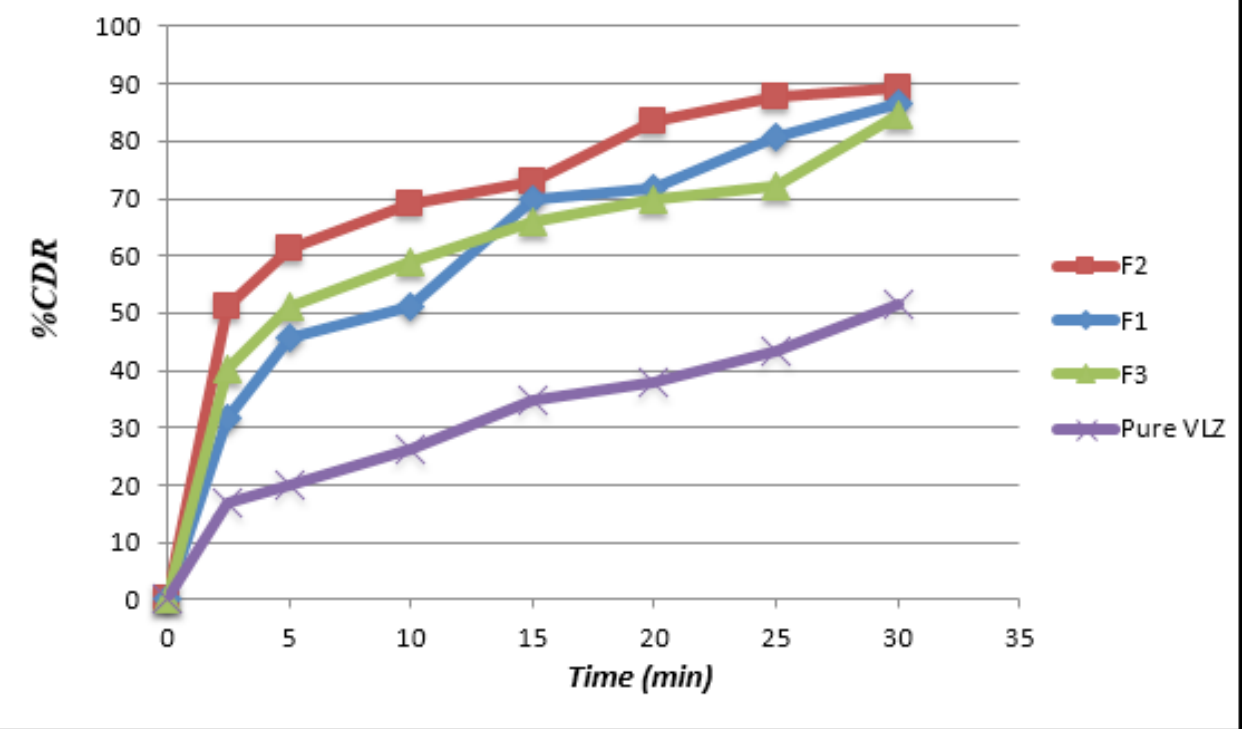

Fig. 10: Comparative Dissolution Profile of VLZ and VLZNPs tablet Formulation.

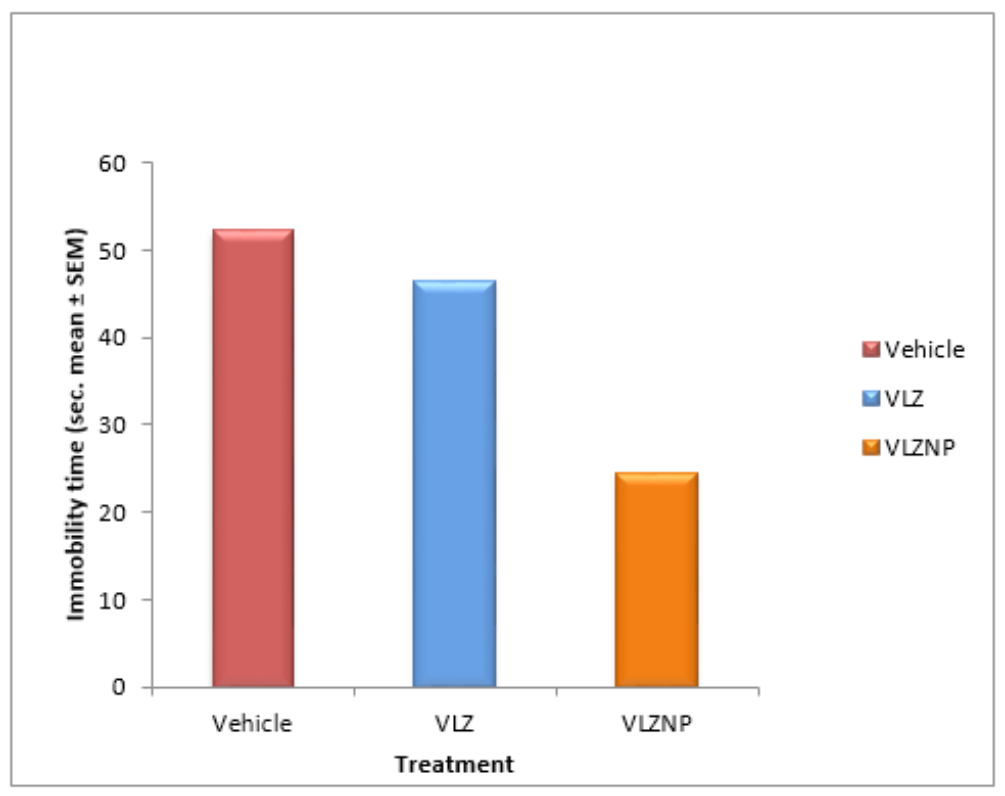

Fig. 11: The Comparative effect of Vehicle, VLZ, and VLZNP on immobility time.

\section{CONCLUSION}

Vilazodone was successfully formulated in nanoparticles with desired characteristics of size, shape, with reasonable stability and high entrapment efficiency and significantly greater solubility with faster drug dissolution compared to pure drug. The characterization parameters DSC, XRD, IR, SEM, and particle size confirm that the particles are crystalline in nature with irregular shape and uniform size i.e. below $100 \mathrm{~nm}$ and compatible with other excipients. Dissolution studies showed the maximum release of optimized Vilazodone nanoparticles (NP4) and optimized Vilazodone tablet formulation $\left(\mathrm{F}_{2}\right)$. This may be due to the increased surface area due to decreased particle size and may due to micelle action of Soluplus. Also from in vivo study, it seems that VLZNP elicited significant antidepressant-like activity as compared to VLZ. Thus in vitro data supported by in vivo results. Evaporative precipitation into aqueous solution thus may be a useful approach to produce nanoparticles of poorly soluble drugs.

\section{ACKNOWLEDGMENT}

Authors are thankful to the school of pharmacy, S.R.T.M. University for providing research facilities. 


\section{CONFLICT OF INTEREST}

Authors declare that there is no conflict of interest.

\section{REFERENCES}

Adjei A, Newburger J, Stavchansky S, Martin A. Membrane solubility parameter and in-situ release of theophylline. J Pharm Sci. 1984; 73:742-745.

Amidon GL, Lennernas H, Shah VP, Crison JR. A theoretical basis for a biopharmaceutics drug classification: The correlation of in vitro drug product dissolution and in vivo bioavailability. Pharm Res. 1995; 12:413-420.

Dahan A, Miller JM. The Solubility-Permeability Interplay and Its Implications in Formulation Design and Development for Poorly Soluble Drugs. The AAPS Journal. 2012; 14(2):244-251.

Patel BP, Patel DM, Patel JK, Patel JD. Review on techniques which are useful for solubility enhancement of poorly water soluble drugs. International Journal for Research in Management and Pharmacy (IJRMP). 2012; 1(1):56-70.

Chen H, Khemtong C, Yang X, Chang X. Nanonization strategies for poorly water-soluble drugs. Drug Discovery Today. 2011; 16(7-8):35460.

Chen X, Sarkari M, Connie YL. Ketoprofen nanosuspension gels formed by evaporative precipitation into aqueous solution. American Institute of Chemical Engineers Journal. 2006; 52(7):2428-2435.

Chen X, Sarkari M, Connie YL. Ketoprofen nanosuspension gels formed by evaporative precipitation into aqueous solution. American Institute of Chemical Engineers Journal. 2006; 52(7):2428-2435.

Coppola D. Nanocrystal Technology Targets Poorly Watersoluble Drugs. Pharm Tech. 2003; 27:20.

Kumar GP, Krishna KG. Nanosuspensions: The Solution to Deliver Hydrophobic Drugs. International Journal of Drug Delivery. 2011; 3:546-557.

Gao L, Zhang D, Chen M. Drug nanocrystals for the formulation of poorly soluble drugs and its application as a potential drug delivery system. J Nanopart Res. 2008; 10:845-862.

Gao L, Zhang D, Chen M. Drug nanocrystals for the formulation of poorly soluble drugs and its application as a potential drug delivery system. J Nanopart Res. 2008; 10:845-862.

Hackley VA, Clogston DJ. Measuring the Size of Nanoparticles in Aqueous Media Using DLS Gaithersburg. NIST, 2007; 22p.

Hardung H, Djuric D. Soluplus ${ }^{\circledR}$ A novel excipient for hot melt extrusion. Chimicaoggi-chemistry Today. 2010; 28(5):XIV-XV.

Junghanns J-UAH, Muller RH, Nanocrystal technology, drug delivery and clinical applications. International Journal of Nanomedicine. 2008; 3(3):295-309.

Medina JR, Salazar DK, Hurtado M, Cortes AR, DominguezRamirez AM. Comparative in vitro dissolution study of carbamazepine immediate-release products using the USP paddles method and the flowthrough cell system. Saudi Pharmaceutical Journal. 2013; 22:141-147.

Jouyban A, Handbook of solubility data for pharmaceuticals.
Gao L, Zhang D, Chen M. Drug Nanocrystals for formulation of poorly soluble drugs and its application as a potential drug delivery system. Nanopart Res. 2008; 10:845-862.

Lipinski C. Poor aqueous solubility- an industry wide problem in drug discovery. Am. Pharm. Rev. 2002; 5:82-85.

Martin A, Bustmante P, Chun AH. States of matter, Edn. 4, Vol Lippincott William and Wilkins Maryland, 2000. 21-23.

Pandey MM, Kumar GK, Ramakrishan R, Chardet S. Solubility enhancement of felodipine by solid dispersions with novel polymeric solubilizer Soluplus. J. Bioequi. Availab. 2012; 4(3):146.

Porsolt RD, Bertin A, Jalfre M. Behavioral despair in mice: a primary screening test for antidepressants. Arch. Int. Pharmacodyn. Ther. 1977; 229:327-336.

Kumar P, Singh C. A Study on Solubility Enhancement Methods for Poorly Water Soluble Drugs. American Journal of Pharmacological Sciences. 2013; 1(4):67-73.

Shegokar R, Muller RH. Nanocrystals: Industrially feasible multifunctional formulation technology for poorly soluble actives. International Journal of Pharmaceutics. 2010; 399:129-139.

Patel SK, Kumar D, Waghmode AP, Dhabale AS. Solubility enhancement of ibuprofen using hydrophobic agents. Int. J. of Pharm. \& Life Sci. (IJPLS). 2011; 2(2):542-545.

Soluplus, Technical information, Pharma ingredients \& services, BASF, the chemical company. 2010.

United States Pharmacopiea, US Pharmaceutical Convention, Rockville, MD. 2002.

USP 30, NF 25 Rockvillle, MD, USA: The United States Pharmacopeial Convention Inc. 2007.

Van de Waterbeemd H, Testa B. Drug bioavailability: estimation of solubility, permeability, absorption and bioavailability. VCH Pub. 2008.

Chen X, Vaughn JM, Yacaman MJ, Williams RO III, Johnston KP. Rapid dissolution of high-potency Danazol particles produced by evaporative precipitation into aqueous solution. J. Pharm. Sci. 2004; 93(7):1867-1878.

Javadzadeh Y, Jafari-Navimipour B, Nokhodchi A. Liquisolid technique for dissolution rate enhancement of a high dose water-insoluble drug (carbamazepine). International Journal of Pharmaceutics. 2007; 341 26-34.

Gattani S, Moon R. Formulation and in vitro evaluation of tablet containing gliclazide nanocrystals for solubility and dissolution enhancement using Soluplus. IJPSR. 2018; 9(1):133-139.

How to cite this article:

Gattani SG, Moon RS. Formulation and Evaluation of Fast Dissolving Tablet Containing Vilazodone Nanocrystals for Solubility and Dissolution Enhancement Using Soluplus: In vitro-In vivo Study. J App Pharm Sci, 2018; 8(05): 045-054. CRC. 2009. 